\title{
Problems concerning assessment of anatomical site of accessory pathway in Wolff-Parkinson-White syndrome
}

\author{
R. A. J. Spurrell, ${ }^{1}$ D. M. Krikler, ${ }^{2}$ and E. Sowton \\ From The Cardiac Department, Guy's Hospital, London
}

Two patients with type $B$ WPW syndrome and reciprocal tachycardias have been studied using intracardiac electrograms and programmed electrical stimulation of the heart. One patient, who had a right-sided accessory pathway giving the surface electrocardiographic appearances of type $B W P W$ syndrome, was shown to have an additional left-sided accessory pathway as occurs in type AWPW syndrome. This concealed left-sided atrioventricular connexion formed the retrograde pathway during reciprocal tachycardia. In the second patient the appearances of type $B$ WPW syndrome were shown to be caused by an accessory pathway between the atrial septum and the right side of the interventricular septum rather than an accessory pathway in the right atrioventricular groove. The significance of these findings when considering surgical interruption of an accessory atrioventricular conduction pathway is discussed.

In the Wolff-Parkinson-White (WPW) syndrome the surface electrocardiogram shows a short PR interval and a wide bizarre QRS complex and there is a tendency to paroxysmal tachycardia (Wolff, Parkinson, and White, I930); the onset of QRS is deformed by a delta wave (Segers, Lequime, and Denolin, 1944). It is now thought that this abnormal complex is caused by fusion between activation of the ventricles via the normal atrioventricular node His pathway and an accessory atrioventricular pathway (Wolferth and Wood, 1933; Butterworth and Poindexter, 1942). The WPW syndrome has been divided into types $\mathrm{A}$ and $\mathrm{B}$ depending upon the QRS configuration in the right praecordial leads (Rosenbaum et al., 1945): in type A, the QRS complex is dominantly positive in VI and V2, whereas in type $B$ it is dominantly negative. Histological examination of hearts from patients with the WPW syndrome has shown that in many instances the location of the accessory pathway can be deduced from the surface electrocardiogram, the accessory pathway classically being in the right atrioventricular groove in type B (Lev, Gibson, and Miller,

Received 5 July 1974 .

${ }^{1}$ Present address: Cardiac Department St. Batholomew's Hospital, London ECI.

${ }^{2}$ Present address: Cardiovascular Division, Royal Postgraduate Medical School, Hammersmith Hospital, London WI2.
I955) and in the left atrioventricular groove in type A (Mann et al., 1973; Ohnell, 1944).

We now describe two patients with the surface electrocardiographic appearances of type B WPW syndrome: an electrophysiological study revealed that one patient had an additional accessory pathway on the left side of the heart (as well as one on the right side) and that in the other case the accessory pathway was not in the right atrioventricular groove but that it connected the right atrium directly with the right side of the interventricular septum.

\section{Patients and methods}

The clinical details of the two patients studied are shown in the Table. Both patients had long-standing histories of paroxysmal supraventricular tachycardia. Informed consent was obtained from both patients and an electrophysiological study was then carried out in the postabsorptive, non-sedated state.

Three bipolar catheter electrodes with an interelectrode distance of $\mathrm{I} \mathrm{cm}$ were introduced percutaneously via one or both femoral veins. One catheter was positioned high in the right atrium to record a high right atrial electrogram; one catheter was positioned across the tricuspid valve and a His bundle electrogram recorded using the technique described by Scherlag et al. (1969). A third catheter was used for atrial or ventricular pacing and for introducing atrial or ventricular premature beats. In Case I a fourth bipolar electroed catheter was passed to the left atrium via a patent foramen ovale and positioned in the region of the left 
TABLE

\begin{tabular}{lllll}
\hline $\begin{array}{l}\text { Case } \\
\text { No. }\end{array}$ & $\begin{array}{l}\text { Age } \\
(y r)\end{array}$ & Sex & $\begin{array}{l}\text { Electro- } \\
\text { cardiogram }\end{array}$ & Clinical details \\
\hline I & 26 & M & Type B WPW & $\begin{array}{c}\text { Recurrent bouts of } \\
\text { supraventricular } \\
\text { tachycardia; mitral } \\
\text { stenosis and aortic } \\
\text { incompetence } \\
\text { Recurrent bouts of } \\
\text { supraventricular } \\
\text { tachycardia }\end{array}$ \\
\hline
\end{tabular}

superior pulmonary vein to record a high left atrial electrogram.

All recordings were made on an eight channel Elema Mingograf 8r. The His bundle electrogram was recorded with the frequency response set at $45-500$ cycles/s. Leads I, III, VI, and V6 of the surface electrocardiogram were recorded simultaneously with the intracardiac recordings. All recordings were taken at a paper speed of $100 \mathrm{~mm} / \mathrm{s}$.

A Devices ${ }^{1} 4270$ stimulator was used for atrial and ventricular pacing. The heart was driven at a constant frequency, thus preventing any changes in excitability or refractoriness caused by irregularities in rhythm. Single or double atrial or ventricular premature beats were delivered after every eighth beat of the basic driven rhythm. A variable delay circuit triggered by either the $R$ wave of the surface electrocardiogram, or an atrial electrogram was used so that the premature beats could be delivered in the cardiac cycle at a preset delay following the preceding driven beat. In each patient the mode of initiation and termination of tachycardia was studied as was the effect of premature beats on the basic rhythm during tachycardia. Pacing of the His bundle was carried out in both patients using the catheter electrode that recorded the His bundle electrogram.

\section{Results}

\section{Case I}

Fig. I is a recording obtained from Case I during right atrial driving. The first two beats are right atrial paced beats with a cycle length of $6 \mathrm{ro} \mathrm{ms}$. The third beat is a right atrial premature beat with a coupling time of $360 \mathrm{~ms}$. The His potential following this atrial premature beat occurs Io $\mathrm{ms}$ after the onset of ventricular activation ( $\mathrm{HV}=-\mathrm{IO} \mathrm{ms}$ ) indicating that this is a fusion beat between impulses conducted down the atrioventricular nodal His system and down the accessory pathway. The QRS complex of this third beat shows a pronounced delta wave in leads I and V6, the QRS is wide, and there is a prodominant $S$ wave in lead VI indicating a typical type B WPW configuration. Fig. 2 is a recording obtained from Case I during right atrial ${ }^{1}$ Devices Instruments Ltd., Welwyn Garden City, Herts.

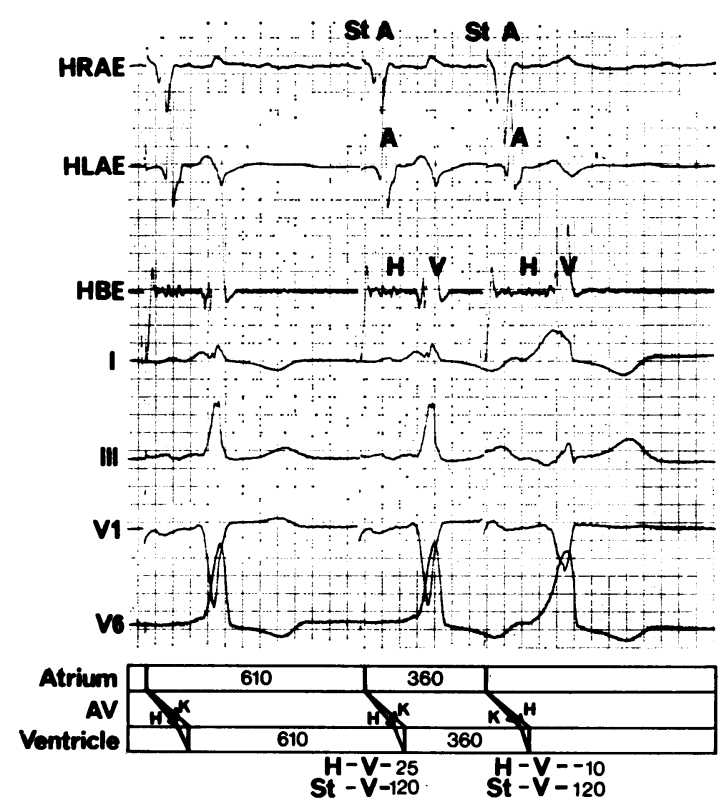

FIG. I Recording obtained from Case I during right atrial pacing with a right atrial premature beat with a coupling time of $360 \mathrm{~ms}$. $H R A E=$ high right atrial electrogram; $H L A E=$ high left atrial electrogram; $H B E=H$ is bundle electrogram; I, III, VI, V6 = surface electrocardiographic leads; St $=$ pacemaker stimulus artefact; $A=$ atrial potential as seen on the atrial electrograms; $H=H i$ potential as seen on the $H B E ; V=v e n t r i c u l a r$ depolarization as seen on the HBE; $H V=$ time in ms from the His potential on the $H B E$ to the earliest onset of ventricular activation; St-V=time in ms from the pacemaker stimulus artefact to the earliest onset of ventricular activation. $A$ self-explanatory ladder diagram is drawn below the recording. $A V=$ atrioventricular region; $H=A V$ nodal His pathway; $K=K$ Kent pathway.

pacing. Again the first two beats are right atrial paced beats with a cycle length of 6ro ms. The third beat is an atrial premature beat with a coupling time of $350 \mathrm{~ms}$, Io ms earlier than in Fig. I. The third QRS complex, however, now has a totally different configuration from the third QRS in Fig. I. Again there is a delta wave, now seen in all four surface electrocardiogram leads; the QRS complex is wide and now there is a positive delta wave and dominant $\mathbf{R}$ wave in lead VI indicating a typical type A WPW configuration.

Fig. 3 is a recording obtained from Case $I$ during right atrial pacing. Again the first two beats are right atrial paced beats with a cycle length of $6 \mathrm{ro}$ ms. His bundle activation occurs simultaneously with the onset of ventricular activation $(\mathrm{HV}=0)$ indicating that these two beats are fusion beats. The 

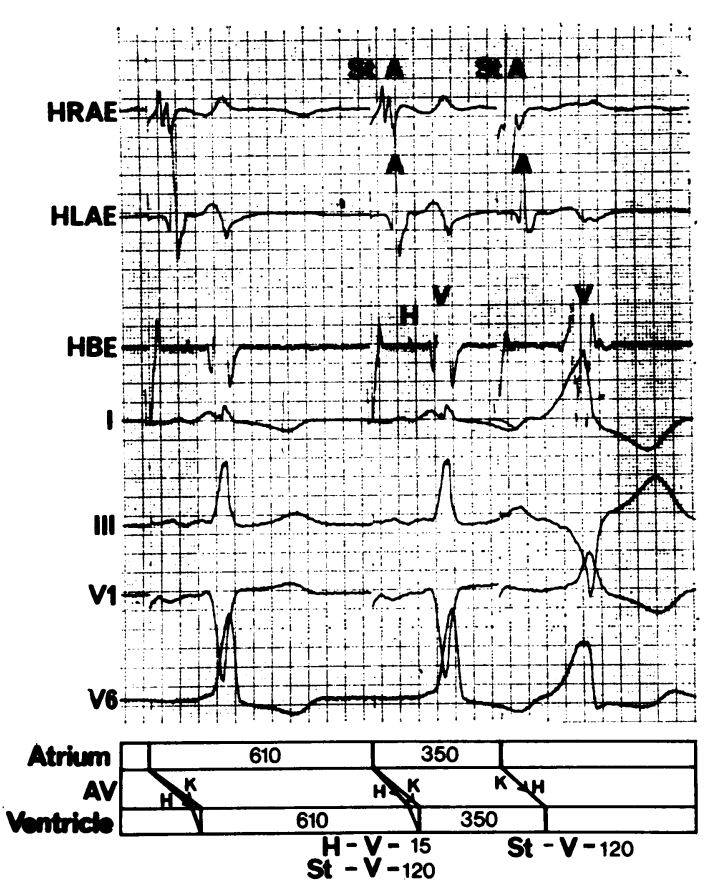

FIG. 2 Recording obtained from Case I during right atrial pacing and with a right atrial premature beat with a coupling time of $350 \mathrm{~ms}$. For explanation, see text.

third beat is a right atrial premature beat with a coupling time of $230 \mathrm{~ms}$. Following this right atrial premature beat, ventricular activation occurs solely by way of the atrioventricular node-His pathway as indicated by the fact that the His potential precedes a normal and narrow $Q R S$ complex by a normal interval $(\mathrm{HV}=45 \mathrm{~ms})$. Following this atrial premature beat there is spontaneous retrograde conduction to the atria as shown on the atrial electrogram and a tachycardia is initiated. During tachycardia the QRS complexes are normal in width and configuration and are preceded by His potentials, indicating that anterograde conduction is by way of the normal atrioventricular node His pathway. The sequence of retrograde atrial activation following each QRS complex as seen on the high right atrial electrogram and high left atrial electrogram is such that the high left atrium is activated $45 \mathrm{~ms}$ before high right atrial activation (retrograde conduction time to the high left atrium VA' (HLA)= 90, whereas retrograde conduction time to the high right atrium $\left.\mathrm{VA}^{\prime}(\mathrm{HRA})=135 \mathrm{~ms}\right)$. The significance of this latter finding will be discussed.

In this patient the tachycardia could be terminated by suitably timed single right and left atrial premature beats and by suitably timed right ventricular premature beats.

\section{Case 2}

Fig. 4 is a surface electrocardiogram obtained from Case 2 during sinus rhythm. The PR interval is short (0.10 s), the QRS complex is wide (0.14 s), and a delta wave can be seen in many leads. In lead VI there is a small $r$ wave and a deep $S$ wave. This electrocardiogram shows a typical type B WPW configuration.

Fig. 5 is a recording obtained from Case 2 during right atrial pacing. The first two beats are right atrial paced beats with a cycle length of $570 \mathrm{~ms}$. Both these right atrial paced beats show the typical features of type B WPW configuration. The third beat is a right atrial premature beat with a coupling time of $280 \mathrm{~ms}$. The QRS complex following this right atrial premature beat is narrow and normal in configuration, indicating that the impulse from this atrial premature beat is conducted solely by way of the atrioventricular node His pathway. Following this atrial premature beat there is a spontaneous retrograde conduction to the atria, as shown on the high right atrial electrogram, and a tachycardia is initiated. During tachycardia anterograde conduction occurs solely by way of the atrioventricular node His pathway, as indicated by the normal and narrow QRS complex preceded by a His potential with a normal $\mathrm{HV}$ time ( $\mathrm{HV}=45 \mathrm{~ms})$. Following each QRS complex there is a retrograde conduction to the atria, as shown on the high right atrial electrogram. The tachycardia in this patient could be consistently terminated by suitably timed right ventricular premature beats, and induced right atrial and right ventricular premature beats during tachycardia were followed by pauses less than compensatory.

Fig. 6 shows a sinus beat, a His bundle paced beat, and a right ventricular paced beat from Case 2. The left hand panel shows a sinus beat which has the typical appearance of a type B WPW syndrome with a short PR interval, wide QRS complex, delta wave, and dominant $S$ wave in lead VI as in Fig. 4. The middle panel shows a beat paced from the region of the His bundle using the catheter that recorded His bundle activity: the QRS complex is identical to that seen in the left hand panel, showing the sinus beat, apart from a minute $\mathrm{q}$ wave in lead III. That ventricular activation occurs simultaneously with the pacemaker stimulus is indicated by the St-V time of o ms. There is retrograde conduction to the atria from this stimulated beat as seen by the atrial activation on the high right atrial electrogram; the retrograde conduction time $\left(\mathrm{VA}^{-}\right)$ is $90 \mathrm{~ms}$. The right hand panel shows a beat obtained when the region between the right ventricular inflow and outflow tract was stimulated. This was carried out by advancing the catheter, through 


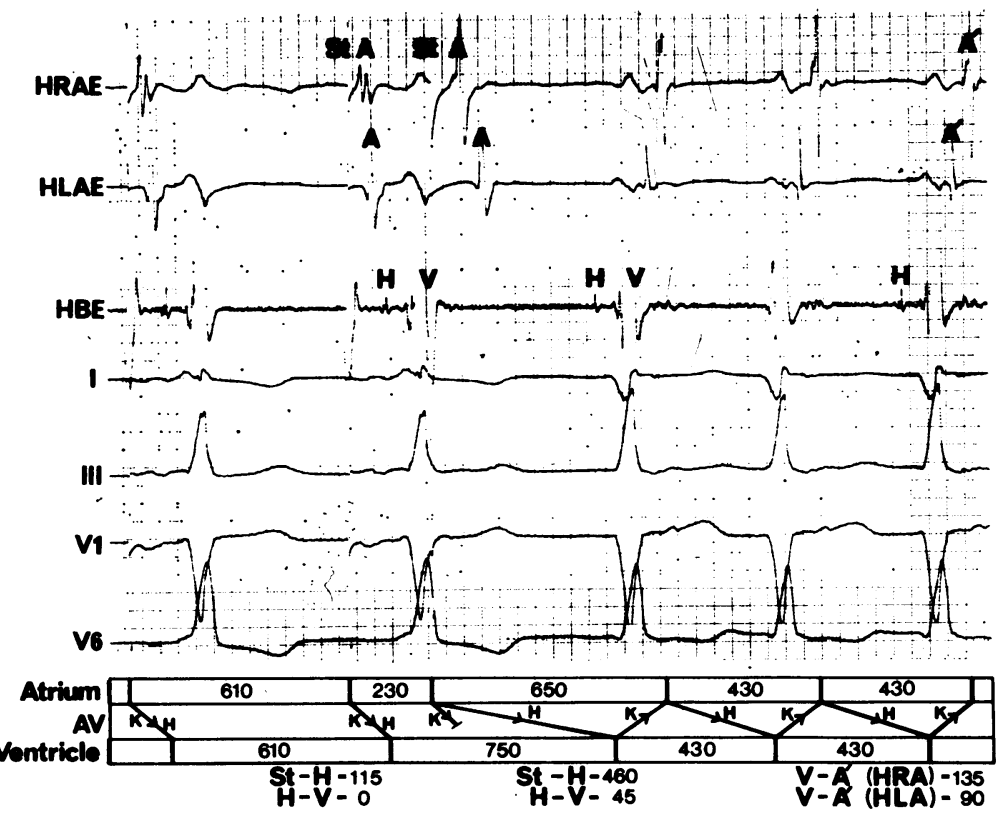

FIG. 3 Recording obtained from Case I showing the onset of a supraventricular tachycardia following an atrial premature beat with a coupling time of $230 \mathrm{~ms}$. $A^{\prime}=$ retrograde atrial potentials as seen on the atrial electrograms; St-H=time in milliseconds from the pacemaker stimulus artefact to the His potential on the $H B E ; V A^{\prime}(H R A)=$ retrograde conduction time in $m s$ from the onset of ventricular activation to the retrograde atrial potential on the HRAE; $V A^{\prime}(H L A)=$ retrograde conduction time in ms from the onset of ventricular activation to the retrograde atrial potential on the high left atrial electrogram.
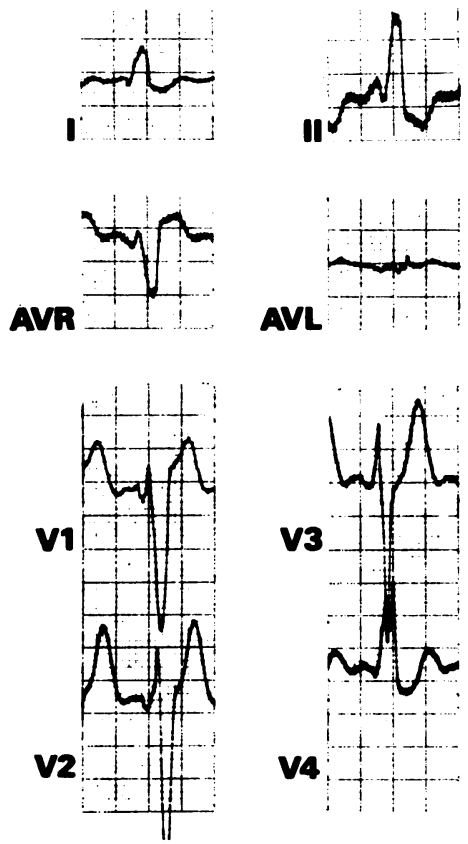

AV
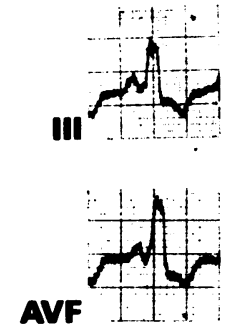

FIG. 4 Surface electrocardiogram obtained during sinus rhythm from Case 2. which the region of the His bundle had been stimulated, I to $2 \mathrm{~cm}$ into the right ventricle. The QRS complex is now seen to be quite different from that of the sinus beat and from the QRS complex resulting from pacing in the region of the His bundle. The QRS complex in the right hand inset now shows a left bundle-branch block pattern with right axis deviation, as may occur with pacing in this region. Following this ventricular paced beat, there is retrograde conduction to the atria as indicated by retrograde atrial activation on the high right atrial electrogram. The retrograde conduction time is considerably longer than when pacing from the region of the His bundle was undertaken $\left(\mathrm{VA}^{\prime}=\right.$ I $70 \mathrm{~ms}$ as opposed to $\mathrm{VA}^{\prime}=90 \mathrm{~ms}$ ).

\section{Discussion}

Patients with intractable tachycardias associated with the WPW syndrome can now be treated by surgical section of the accessory pathway. During epicardial mapping studies in a patient with type B WPW syndrome, Cobb et al. (1968) found an area of ventricular pre-excitation in the right atrioventricular groove; when this area was divided 


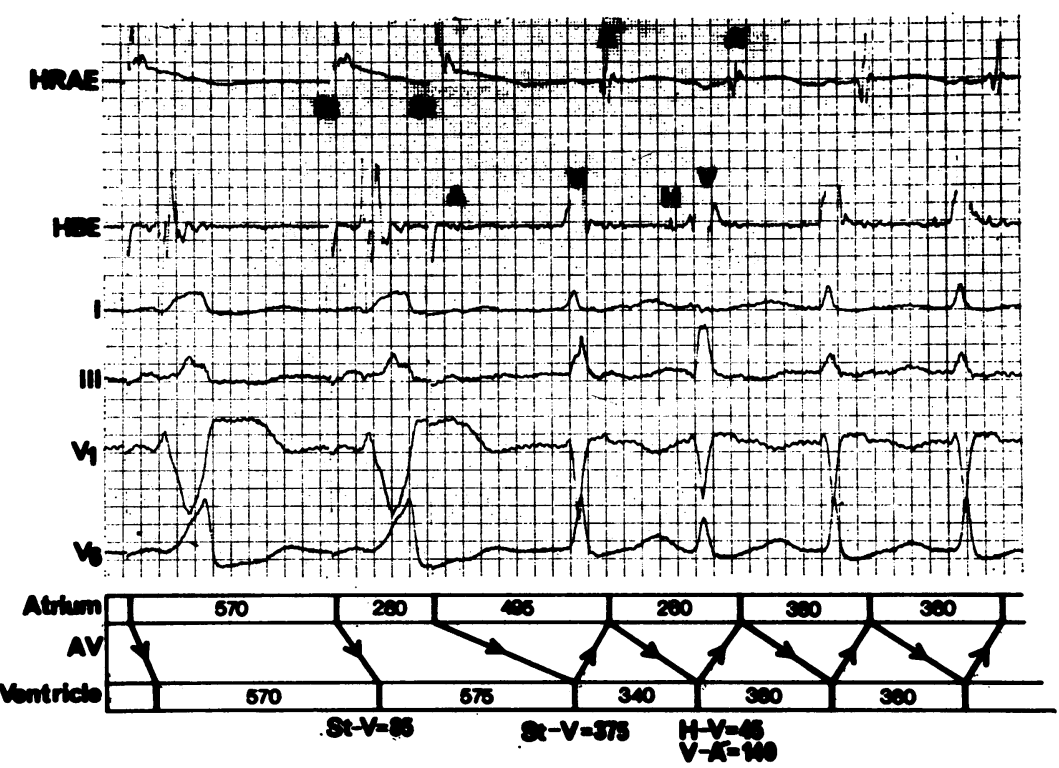

F I G. 5 Recording obtained from Case 2 showing the initiation of a supraventricular tachycardia by a right atrial premature beat with a coupling time of $280 \mathrm{~ms}$. VA' $=$ retrograde conduction time in ms from the earliest onset of ventricular activation to the retrograde atrial potential on the high right atrial electrogram.

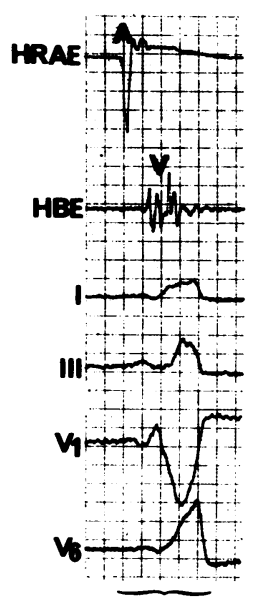

Sinus Phythm
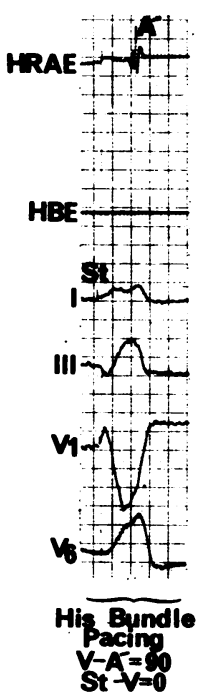

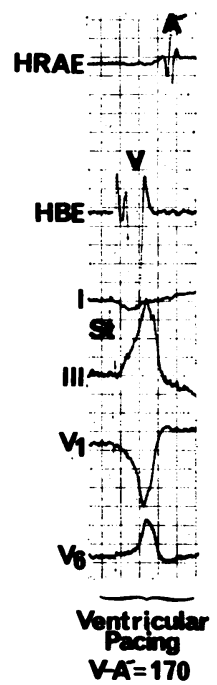

FIG. 6 Recordings obtained from Case 2 showing a sinus beat in the left hand panel, a His bundle paced beat in the centre panel, and a beat obtained from stimulation of the right ventricular inflow tract in the right hand panel.
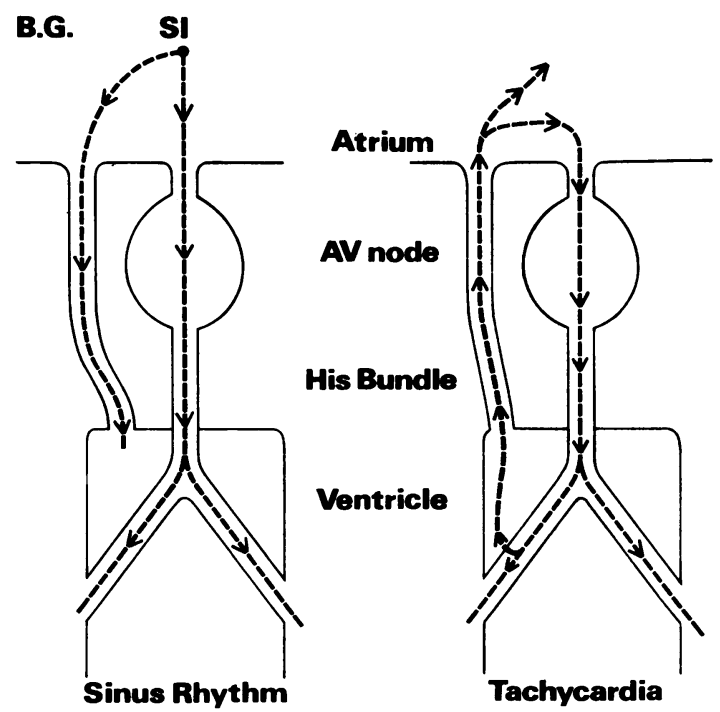

FIG. 7 Diagram of the normal conduction system and the accessory atrioventricular connexion in Case 2 showing the conduction sequence (interrupted line) during sinus rhythm in the left hand panel and during tachycardia in the right hand panel. SI=sinus impulse. 
surgically the pre-excitation and episodes of tachycardia were abolished. Since then other workers have had similar success in patients with type B WPW. More recently, Wallace et al. (1974) have reported two patients with type A WPW syndrome in whom epicardial mapping studies showed an area of ventricular pre-excitation posteriorly in the left atrioventricular groove; appropriate atrial incisions were made, and the pre-excitation and episodes of tachycardia were abolished.

This form of therapy depends upon the accurate assessment of the site and function of the accessory pathway. In the first patient described in this paper the resting surface electrocardiogram showed a type B WPW configuration and classically the accessory pathway would be expected to occur in the right atrioventricular groove. It would have been reasonable to expect that the circus movement tachycardia occurring in this patient involved retrograde conduction by way of this right-sided accessory pathway. Had epicardial mapping been carried out in this patient, an early area of ventricular activation may well have been found in the right atrioventricular groove and surgery carried out in this region. Initially the electrophysiological study demonstrated that during sinus rhythm and with atrial premature beats down to a coupling time of $360 \mathrm{~ms}$ the ventricles were activated via a rightsided accessory pathway giving the appearance of a type B WPW syndrome. However, with atrial premature beats occurring at coupling times of $350 \mathrm{~ms}$ and less (Fig. 2), this right-sided accessory pathway became refractory and the ventricles were then activated via a left-sided accessory pathway, now with the surface electrocardiographic appearances of type A WPW syndrome. This latter configuration of type A WPW syndrome was never seen on resting electrocardiograms. An unusual feature, however, concerns the stimulus to delta interval $(\mathrm{St}-\mathrm{V})$ of the beats showing a type B WPW configuration and those showing a type $A$ configuration. In both instances this interval is the same $(\mathrm{St}-\mathrm{V}=120 \mathrm{~ms})$. In the presence of a left-sided accessory pathway it would be expected that the conduction time from a right atrial stimulus to the atrial insertion of a left-sided accessory pathway would be longer than the conduction time to a rightsided accessory pathway. The lack of prolongation of the St-V time in this patient when left-sided accessory pathway activation occurs may be caused by the atrial end of both pathways being inserted relatively close together, possibly posteriorly, one into the right atrium and the other into the left. At an atrial premature beat coupling time of $230 \mathrm{~ms}$ this left-sided accessory pathway also became refractory and the ventricles were activated solely by way of the atrioventricular node His pathway, and a re-entry tachycardia was initiated. During tachycardia it is conceivable that retrograde conduction would occur by way of either the left- or rightsided accessory pathway, or the re-entry circuit could be intra-atrioventricular nodal with neither accessory pathway involved. However, the retrograde activation sequence of the atria during tachycardia was such that the high left atrium was activated $45 \mathrm{~ms}$ in advance of the high right atrium (see Fig. 3), suggesting that the retrograde pathway inserted into the left atrium. In addition, this patient had mitral valve disease with an enlarged left atrium. Under these circumstances, one would expect retrograde atrial activation in the region of the left superior pulmonary vein (the site of the left atrial recording electrode) to be delayed. In this patient, the high left atrium was still activated in advance of the right and in the presence of a normal left atrial size the high left atrial activation would occur even earlier still, thereby emphasizing further the abnormal retrograde atrial activation sequence with high left atrial activation occurring before the right. A similar retrograde atrial activation sequence during tachycardia was found by Wallace et al. (1974) in two patients with type A WPW syndrome. It has been found in our laboratory that during re-entry tachycardia in type $B$ WPW syndrome retrograde right atrial activation invariably precedes left atrial activation and in atrioventricular nodal re-entry tachycardia activation of the high right and high left atria occurs either simultaneously or the right atrium is activated in advance of the left. These findings accord well with those of Massumi et al. (1969) who found that during right ventricular pacing in patients with normal conduction systems retrograde activation of the atria by way of the atrioventricular node His pathway led to simultaneous right and left atrial activation, or right atrial activation occurred up to $30 \mathrm{~ms}$ before left atrial activation. It appears, therefore, that Case I has two accessory pathways, one giving the appearance of type B WPW syndrome on the resting electrocardiogram; the other which probably lies in the left atrioventricular groove is only apparent following early right atrial premature beats. However, it is this concealed leftsided accessory pathway which provides the retrograde pathway for the reciprocal circuit during tachycardia.

Mulptiple anomalous atrioventricular connexions have been identified in the rabbit (Sano, Suzuki, and Tsuchihasi, 1970) and squirrel monkey (Boineau et al., 1973). Appearances may be seen in man suggestive, at different times, of WPW syndrome types A and B (Ramachandran, 1972); but in a 
more convincing report, Matter and Hayes (1964), recorded on three separate occasions, surface electrocardiograms that, respectively, showed normal conduction, WPW syndrome type A, and WPW syndrome type $B$, in a patient suffering from paroxysmal supraventricular tachycardia. Intermittent and unexplained transformation from type A to type $B$ has recently been observed during a physiological study (Josephson, Caracta, and Lau, I974).

In the second patient, also with the surface electrocardiographic appearances of type B WPW syndrome, an accessory atrioventricular connexion in the right atrioventricular groove would be expected. During right atrial pacing $(\mathrm{St}-\mathrm{V}=85 \mathrm{~ms})$ anomalous activation of the ventricles occurred as shown by the short PR interval, delta wave, and wide QRS complex (Fig. 5), but an atrial premature beat at $\mathbf{2 8 0} \mathrm{ms}$ found the accessory pathway refractory and the ventricles were then activated solely by way of the AV node His pathway. Following this atrial premature beat, a tachycardia was initiated which showed normal QRS complexes. During tachycardia induced premature beats were followed by pauses less than compensatory and the tachycardia could be terminated by suitably timed single premature beats. These findings suggested that a reentry or reciprocal mechanism was the most likely basis for the tachycardia (Wellens, 197I). In this patient, therefore, the reciprocal circuit during tachycardia is likely to be anterogradely via the atrioventricular nodal His pathway and retrogradely via the accessory pathway.

If the accessory pathway is in the atrioventricular groove, then stimulation in the region of the bundle of His (via the electrode recording the His bundle electrogram) will only stimulate the normal conduction system and a narrow QRS complex will be seen on the surface electrocardiogram. However, the middle inset (Fig. 6) shows that during His bundle pacing a QRS complex identical to that occurring during anomalous activation of the ventricles is seen; this suggests that the accessory pathway was activated during stimulation in the region of the bundle of His.

Coumel et al. (197I) have demonstrated that the occurrence of a short $\mathrm{HV}$ time in association with a delta wave and a normal QRS complex during His bundle stimulation suggests the presence of a Mahaim bypass close to the His bundle and inserting into the ventricular septum (Mahaim, 1947). Cole et al. (1970) provided evidence that an accessory connexion between the atrial septum and ventricular septum existed in a patient with the electrocardiographic appearance of a type B WPW syndrome but in whom epicardial mapping showed an early area of ventricular activation in the right atrioventricular groove. This conforms with the suggestion by Durrer, Schuilenburg, and Wellens (I970) that the surface electrocardiographic features of type B WPW syndrome could result from ventricular septal pre-excitation.

In Case 2 the anomalous activation of the ventricle is most probably caused by an accessory pathway inserting into the right side of the interventricular septum which gives the surface electrocardiographic appearance of a type B WPW syndrome both during sinus rhythm and during stimulation in the region of the His bundle. During stimulation in the region of the His bundle the time from the stimulus artefact to the onset of ventricular activation $(\mathrm{St}-\mathrm{V})$ was $\circ \mathrm{ms}$, indicating that the stimulation must be occurring at the ventricular end of the accessory pathway.

That the surface electrocardiographic appearances during stimulation in the region of the His bundle are not caused by direct ventricular stimulation mimicking anomalous activation of the ventricle is shown by totally different QRS configuration produced by stimulation of the inflow tract of the right ventricle (right hand inset, Fig. 6).

During stimulation in the region of the His bundle, the retrograde conduction time from the onset of ventricular activation to high right atrial activation is short $\left(\mathrm{VA}^{\prime}=90 \mathrm{~ms}\right)$. This suggests that the upper part of the accessory pathway inserts directly into the atrium rather than inserting either into the atrioventricular node or upper part of the His bundle; in the latter two instances the retrograde conduction time would be expected to be longer because of retrograde conduction through the atrioventricular node.

Fig. 7 is a diagram showing the position of the accessory pathway. During sinus rhythm (left hand diagram) the ventricles are activated via the normal atrioventricular node $H$ is pathway and via the accessory pathway passing from the atrium to the upper part of the right side of the intraventricular septum, thus giving the surface electrocardiographic features of type B WPW syndrome. During reciprocal tachycardia anterograde conduction occurs by way of the atrioventricular node His pathway, the surface electrocardiogram showing a normal and narrow QRS complex preceded by a His potential, and retrograde conduction occurs by way of the accessory pathway.

During tachycardia the retrograde conduction time $\left(\mathrm{VA}^{\prime}\right)$ is $140 \mathrm{~ms}$ which is $50 \mathrm{~ms}$ longer than the retrograde conduction time during stimulation in the region of the His bundle $\left(\mathrm{VA}^{\prime}=90 \mathrm{~ms}\right)$. This additional $50 \mathrm{~ms}$ is most probably caused by the conduction time in the septum from the site at which 
the activation impulse leaves the right bundlebranch to the ventricular insertion of the accessory pathway (see Fig. 7).

Atrioseptal accessory pathways were described by Paladino in I914 and more recently by Schumann, Jansen, and Anschutz (1970). It appears that an atrioseptal accessory pathway of the type postulated in this patient may be similar to that found by Cole et al. (1970), as described earlier in the discussion.

The findings in these two patients, therefore, indicate the importance of an adequate electrophysiological study in patients with the WPW syndrome who are under consideration for surgical division of the accessory pathway. In the first patient an accessory pathway in the right atrioventricular groove may have been found and divided at surgery, but an attempt to divide the additional concealed left-sided accessory pathway, the one responsible for the reciprocal tachycardia, would not have been made unless it had been demonstrated before operation; thus attacks of tachycardia may have persisted. In the second patient the accessory pathway was not in the classical site of a Kent pathway in the atrioventricular groove but was adjacent to the normal specialized conduction system inserting into the upper part of the ventricular septum. If this situation had not been assessed adequately before operation then an unsuccessful attempt to divide an accessory pathway in the right atrioventricular groove may have been made, especially if epicardial mapping had shown an early area of ventricular excitation in the right atrioventricular groove, as was the case in the patient described by Cole et al. (1970), and discussed earlier. In this patient, a possible surgical approach would be to attempt to divide the accessory pathway between the atrium and the upper part of the right side of the interventricular septum, but such an approach would be extremely difficult without causing additional damage to the normal specialized conduction system in this region, thereby possibly necessitating the implantation of a pacemaker.

As has been indicated previously (Spurrell, Krikler, and Sowton, I973), even in the presence of an anomalous pathway, paroxysmal tachycardia may depend exclusively on pathways within the atrioventricular node. Before surgery is contemplated for the treatment of refractory tachycardia, it is essential not only to identify such pathways as may be present, but also to demonstrate that they are implicated in the tachycardia circuit. Unless this is done, what appears to be a justifiable surgical procedure may fail, not because of poor surgical technique, but because the mechanism of the tachycardia has not been completely defined by rigorous electrophysiological study.

\section{References}

Boineau, J. P., Moore, E. N., Spear, J. F., and Sealy, W. C. (1973). Basis of static and dynamic electrocardiographic variations in Wolff-Parkinson-White syndrome. American fournal of Cardiology, 32, 32.

Butterworth, J. S., and Poindexter, C. A. (1942). Short PR interval associated with a prolonged QRS complex. Archives of Internal Medicine, 69, 437.

Cobb, F. R., Blumenschein, S. D., Sealy, W. C., Boineau, J. P., Wagner, G. S., and Wallace, A. G. (1968). Successful surgical interruption of the bundle of Kent in a patient with Wolff-Parkinson-White syndrome. Circulation, 38, ror 8.

Cole, J. S., Wills, R. E., Winterscheid, L. C., Reichenbach, D. D., and Blackmon, J. R. (1970). The Wolff-ParkinsonWhite syndrome; problems in evaluation and surgical therapy. Circulation, 42, II I.

Coumel, P., Waynberger, M., Slama, R., and Bouvrain, Y. (I971). Interet de l'enregistrement des potentiels Hisiens au coeurs du syndrome de Wolff-Parkinson-White a propos de six observations. Acta Cardiologica, 26, 188.

Durrer, D., Schuilenburg, R. M., and Wellens, H. J. J. (1970). Pre-excitation revisited. American fournal of Cardiology, 25, 690.

Josephson, M. E., Caracta, A. R., and Lau, S. H. (1974). Alternating type $A$ and type $B$ Wolff-Parkinson-White syndrome. American Heart fournal, 87, 363.

Lev, M., Gibson, S., and Miller, R. A. (1955). Ebsteins disease with Wolff-Parkinson-White syndrome. American Heart Fournal, 49, 724.

Mahaim, I. (1947). Kent's fibers and the AV paraspecific conduction through the upper connections of the bundle of His-Tawara. American Heart fournal, 33, $65 \mathrm{I}$.

Mann, R. B., Fisher, R. S., Scherlis, S., and Hutchins, G. M. (1973). Accessory left atrioventricular connection in type A Wolff-Parkinson-White syndrome. fohns Hopkins Medical fournal, 132, 242.

Massumi, R. A., Sarin, R. K., Tawakkol, A. A., Rios, J. C., and Jackson, H. (I969). Time sequence of right and left atrial depolarization as a guide to the origin of the $P$ waves. American fournal of Cardiology, 24, 28.

Matter, B. J., and Hayes, W. L. (1964). Wolff-ParkinsonWhite syndrome. Report of a case with both type $A$ and type B pre-excitation. American fournal of Cardiology, 13, 284.

Ohnell, R. F. (1944). Pre-excitation. A cardiac abnormality. Acta Medica Scandinavica, Suppl. 152, 77.

Paladino, G. (1914). Ancora per una questione di priorità a proposito del fascio atrio-ventricolare del cuore. Anatomischer Anzeiger, 46, 90.

Ramachandran, S. (1972). Wolff-Parkinson-White syndrome. Conversion of type A to type B electrocardiographic changes. Circulation, 45, 529.

Rosenbaum, F. F., Hecht, H. H., Wilson, F. N., and Johnston, F. D. (1945). The potential variations of the thorax and the esophagus in anomalous atrioventricular excitation (Wolff-Parkinson-White syndrome). American Heart fournal, 29, 281.

Sano, T., Suzuki, F., and Tsuchihashi, H. (1970). Function of potential bypass tracts for atrioventricular conduction. Circulation, 4I, 413.

Scherlag, B. J., Lau, S. H., Helfant, R. H., Berkowitz, W. D., Stein, E., and Damato, A. N. (1969). Catheter technique for recording His bundle activity in man. Circulation, 39, 13. 
Schumann, G., Jansen, H. H., and Anschutz, F. (1970). Zur pathogenese des WPW syndroms. Virchows Archiv für pathologische Anatomie und Physiologie, 349, 48.

Segers, M., Lequime, J., and Denolin, H. (I944). L'activation ventriculaire précoce de certains coeurs hyperexcitables. Etude de l'onde delta de l'electrocardiogramme. Cardiologia, 8, II 3 .

Spurrell, R. A. J., Krikler, D., and Sowton, E. (1973). Two or more intra AV nodal pathways in association with either a James or Kent extranodal bypass in 3 patients with paroxysmal supraventricular tachycardia. British Heart fournal, 35, 113 .

Wallace, A. G., Sealy, W. C., Gallagher, J. J., Svenson, R. H., Strauss, H. C., and Kasell, J. (1974). Surgical correction of anomalous left ventricular pre-excitation: WolffParkinson-White (Type A). Circulation, 49, 206.
Wellens, H. J. J. (1971). Electrical Stimulation of the Heart in the Study and Treatment of Tachycardia. H. E. Stenfert Kroese NV, Leiden.

Wolferth, C. C., and Wood, F. C. (1933). The mechanism of production of short $P R$ intervals and prolonged QRS complexes in patients with presumably undamaged hearts: hypothesis of an accessory pathway of auriculo-ventricular conduction (bundle of Kent). American Heart fournal, 8, 297.

Wolff, L., Parkinson, J., and White, P. D. (1930). Bundlebranch block with short PR interval in healthy young people prone to paroxysmal tachycardia. American Heart Fournal, 5, 685.

Requests for reprints to Dr. R. A. J. Spurrell, Cardiac Department, St. Bartholomew's Hospital, London E.C.I. 